\title{
Churned and Spurned in the Flexible World of Work A Corporate Narrative
}

\author{
JANE MESSER
}

MACQUARIE UNIVERSITY

\begin{abstract}
IBM offers him a position as a trainee programmer. If he does well in his training course, and then passes his probationary period, he will become first a Programmer proper, then one day a Senior Programmer ... The hours will be nine to five ... In the desk drawer he finds paper, a ruler, pencils, a pencil sharpener, and a little appointment book with a black plastic cover. On the cover, in solid capitals, is the word THINK ... he ought to be happy. In fact, as the weeks pass, he finds himself more and more miserable.
\end{abstract}

In Coetzee's fictionalised memoir, the narrator's reconstruction of his workplace resonates with his feelings of alienation, his young man's disenchantment with the gap between his expectations of the work experience and its actuality, the disappointment of his social relationships at work, and his feelings about the physical environment of his workplace. The narrator 'feels his very soul to be under attack'.2 
While such disenchantment with work remains for many, much has changed since Coetzee started work at IBM in London in the 1960s. The assured security that companies offered, to promotion and lifelong employment, is gone, along with the pencils and paper. What remains is a continuing and, for many, an increasing sense of alienation at work. Accelerated by the new internet technologies, the past two decades have been characterised by a globalisation of trade and communications, along with major shifts in the balance between manufacturing and knowledgedriven economies. ${ }^{3}$ New organisational cultures have grown out of and have reflexively driven these changes, and these new organisational cultures of work are registered and enacted by employees through a plethora of micro-practices in the workplace. While workers are immersed in the meta-shifts in workplace organisation and are personally affected by them, they do not always understand them. There is a dearth of detailed analysis of the grassroots experience of the fragmented and transitory modes of work, of how these mega shifts that we 'know' are occurring at a global level are having an impact on us, and particularly little available with an Australian focus.

So, how are these shifts being experienced at the ground level by the workers who are part of this flexible workforce in transnational organisations? What happens to human subjectivity in these current regimes of flexible accumulation with radically transformed modes of production and consumption and new modes of regulation?4 Are we as flexible as the term 'flexible workforce' implies? We do adapt, but what effects does this have on our sense of self and our understanding of who we are in relation to our work, given that work is a defining experience for self value?

In The Corrosion of Character, sociologist Richard Sennett looks at why new ways of organising working time, the dissolution of the traditional career which progressed step by step, the necessity to change jobs and even one's skills base a number of times in one's working life, and the increase in short term job contractsin short, 'flexibility'-are having profound effects on character. ${ }^{5}$ While it is widely understood that the global restructuring of labour has changed the nature of work, Sennett's emphasis on the lived experience of workers takes this further, enabling us to see some of the ways these organisational shifts and the managerial practices associated with them have very real impacts on everyday life, with profound effects 
on subject formation, and on the way that individuals understand themselves and their social world.

While it is a given that global changes in modes of production and consumption, and in the organisation of labour, are having a profound impact on our lives, the analysis tends to focus on the macro changes, as illustrated in the immediate aftermath debates about the 'global financial crisis' (GFC). Newspaper reports covered popular topics on change, including politicians' and economists' warnings that the crisis would have an impact on our daily lives. The reports assumed there would be direct impacts on our lives but the analysis itself focused on the macro economic changes and the rationale for change, doing little to illuminate our everyday experience. Fleeting television images of American unemployed living in tent camps, and Chinese factory workers returning to the countryside was not sufficiently deep to address these experiences.

Research about how individuals experience their work in environments of change, and how they make (or don't make) sense of it all, could, however, lead to employees themselves being better equipped to address their own alienation. It is potentially empowering to be aware of the links between one's own individual experience (agency) and the macro structure surrounding your own particular micro-experience. But, such an awareness is particularly hard to come by in the modern flexible workplace, with its low rates of unionisation, high rates of demographic mobility, workplace churning, short half-lives of knowledge, and so on.

Narrative is a mode of writing that is a starting point for addressing this gap in felt knowledge, because in helping us have an imaginary about our experience as workers, narrative supports thinking more broadly about the contradictions inherent in our current system of globalised profit chasing and productivity through flexible labour. Narrative can express the benefits and the losses, the elation of achievement or the crisis of retrenchment. Narrative's value lies in the way that it drills down into lived experience to show how individual 'character' is shaped-or even how it might resist the new modes of management. Narrative isn't simply a listing of events, with names and outcomes, it is something that arches over time and embraces places, reveals motivations, causes and consequences; it takes account of how people feel about themselves. 
Sennett uses narrative to cut across the usual discipline boundaries which segregate conceptions of work into either a wage relationship, or an activity of social production, or necessary social labour and so on, and to get to the matter of the individual's experience of self within the new regimes of work. Similarly, the images, observations, interior monologues and other narrative devices in Coetzee's Youth create the narrator's workplace 'imaginary'. What's needed is more contemporary writing to engage with the new regimes of individual's experiences of work; more narratives that pay attention to this aspect of our lived experience. ${ }^{6}$ We need narrative that explores and exposes how the new regimes of work are experienced at the everyday level, at the level of individuals. ${ }^{7}$

Sennett is concerned that the single most corrosive aspect of the new capitalism regime of 'flexibility' is its impact on personal character. ${ }^{8}$ By character he means not the more modern notion of 'personality' with its suggestion of momentary desires and attributes, but character as the long-term aspect of emotional experience, the sustained sentiments of lasting value, and the ethical values we place on our 'own desires and on our relations to others'. Sennett's focus on character enables us to conceive how global structural changes are experienced at an intimate local level, how these major social and economic shifts are registered and from there to consider how they might be resisted at the level of individual subjects.

French psychoanalyst Christophe Dejours' current research focuses on this problem of the invisible in the psychodynamics of work, and his research has affinities with Sennett's, as both are concerned with the impact on the individual of these new regimes of workplace organisation. Dejours begins his discussion on invisibility by demonstrating that it is not possible to describe all that is necessary to undertake to fulfil the tasks of work, whether they be mechanical or intellectual in nature; not in duty statements nor through verbal or demonstrated instructions. He writes:

ordinary work situations are rife with unexpected events, breakdowns, incidents, operational anomalies, organizational inconsistency and things that are simply impossible to predict, arising from the materials, tools, and machines as well as from other workers, colleagues, bosses, subordinates, the team, the chain of authority, the clients, and so on. ${ }^{9}$ 
It is not difficult to recognise in Dejours' description that there's a gap between what we're asked to do and what we give of ourselves to get the work done. A gap lies between the formal and informal organisation of work because work exceeds our paid working hours, or the hours we're at our workplace or formally undertaking tasks.10 This situation may be clearly understood in, for instance, a bakery such as the Baker's Delight franchise, in which not every single situation can be described through procedure manuals or demonstrations. The bakers at the back of the shops and sales staff at the front counter need to contribute their common sense, skills with the baking and slicing machines, affability with customers, cooperation with other staff, and so on. It's valid, too, for those who work in more intellectual or relational kinds of employment, for instance, the service industries, education or sales. ${ }^{11}$

We talk of 'taking work home' with us, we dream about it, or wake thinking of to-do lists, we return home in a particular frame of mind formed by the day's work. We also know how destructive bullying at work is to self esteem and overall enjoyment of life. We know that men and women out of work may feel themselves to be less of a person, to be adrift. Our bodies may be changed for the worse through work, with backache, repetitive strain injuries, skin diseases or stress injuries. Work has these impacts because it 'mobilises' the whole of our personality. ${ }^{12}$ In Dejours' definition, work is what we add of our bodies and intelligence that exceeds what is proscribed.

The invisibility of much of our work hinders articulation of what it's like to participate in the new capitalism work regimes. We don't have to hand new narratives, and the traditional narratives of work that middle-aged and older workers are familiar with are not sufficient now. No wonder it is hard for workers to make sense of their experience and their role-or that they feel alienated-and ultimately it is not surprising that management has so limited a grasp of what the workers' experience is, or that management questions why their employees don't have loyalty to the company, don't stay, or why they're anxious, take sickies, and so on. Or, for that matter, why individuals working in management similarly suffer.

Narrative offers the possibility of validating and making visible the invisible-and the suffering of the subject-that Dejours describes as an inevitable condition of work. Narrative is, after all, one of the primary means in our culture by 
which we make links between the internal life of individuals and the external conditions of experience. The literary critic James Wood has said in a number of his essays that the task of the contemporary social realist novel is to make connections between the inner life of our culture and the inner life of the human, to seek out and address questions of characters in the worlds of work, or family, finance, politics or whatever the writer chooses as her or his focus. ${ }^{13}$ Narrative can address the invisibility of experience within the camouflaged and sometimes illegible systems of power within corporate culture.

In my own ethnographic research, and the writing I have developed from the field and interviews, to address this gap, I've aimed for a local, Australian perspective. Between 2005 and 2009 I interviewed eight men and women working as sales executives for transnational IT companies in Australia, some of them a number of times. ${ }^{14}$ These men and women were responsible for selling systems software to government and private bodies including banks, universities and airlines. Contracts could be worth hundreds of thousands to millions of dollars. Generally they were paid a base salary of between $\$ 100,000$ to $\$ 150,000$, then could earn commissions on sales of $\$ 50,000$ or more.

I was drawn to this industry because it experiences ongoing and intense organisational change; and there is the challenging truth that the industry's organisational and management practices have enabled its innovations. The field of software systems sales work was germane not only because the stakes were high for the individual executives, but also because their 'pseudo autonomy' exposed inherent contradictions and difficulties in their relationship to work. While they had day-to-day autonomy, they were constantly scrutinised and their outputs monitored, they had no influence on company policy, their employment contracts were flimsy, and their managers and HR ruled.

Most of my interviewees were based in Sydney. Each interview took some hours, and I spoke with a few of the executives more than once. I waited about six months to a year before the follow-up interviews to allow for the inevitable changes in employer to occur. My approach focused on eliciting a narrative of their work life-their story. By using open and relatively few questions, each person was able to shape their own narrative. ${ }^{15}$ The participants spoke about how they came to be in sales, who they'd worked for and why they'd left or the ways they'd been 
retrenched, the highs and lows, their family and what they'd 'bought' with their earnings: nice houses, private school education for their children and, in one case, the opportunity to adopt children. I also asked them about the nitty-gritty of what they actually did, their observations on their company's products and management policies, the technologies they used, training, financial rewards, retrenchment and hiring and human resources practices. While the questions were open, with each participant I did return to a few critical questions. Toward the end of the interview, we would discuss their work ethic. ${ }^{16}$ This was an area that was harder for them to negotiate and vocalise, as their ethical contributions were not measured, not valued, sometimes made performance outcomes more difficult to attain, and were essentially invisible.

These interviews could be interpreted as an intervention; some interviewees used the conversation as a means to gain greater insight into their lived experience and their own affective register. In the main they appreciated my interest in their work; their storytelling gave their work and their self-in-work visibility. In speaking to me they could safely articulate their thoughts about their work lives: I was not their boss, colleague, HR supervisor or spouse. They were assured of anonymity through the participant contract. That said, some interviewees were more forthcoming than others. My being a woman made it less likely that certain kinds of information or reflections would arise. I know, for instance, that one fellow used brothels in North Sydney 'to wind down' at lunchtime, only because one of his colleagues told me. He did, however, speak to me about his father dying, presenting himself more as a family man than a 'john'.

Themes emerged in these stories and revelations of character that shared affinities with Sennett's study of American workers' experiences and Dejours with the French. For the Australians, however, there was a greater distanciation at play because major company decisions were initiated outside Australia in head offices in the US and Europe. The Australians were aware of this distance and sometimes noted the cultural differences between American and Australian corporate organisation. This was further confirmation of the importance and need for local narratives to account for the lived experience of local workers in transnational organisations. 
Theorists such as Sennett, David Harvey, Manuel Castells, Frederic Jameson, Nancy Fraser and Anthony Giddens offer compelling macro framework analyses of modernity and subjectivity, showing how it is that we regulate ourselves and participate actively in these regimes. This participation and co-option contributes to my project's challenges. My interviewees experienced these regimes as beneficial and at other times (or even simultaneously) as detrimental. Adrenalin, ambivalence and anxiety were often bundled together. The executives needed to both withstand and profit from the impact of their companies' globalised ownership and 'flexible' employment management structures. They had reservations about their industry, and they recognised how damaging it was to others they knew and possibly how damaged by it they were; but they also enjoyed the money, the travel rewards and the days of success. This was how they were different to Coetzee's narrator: his young man wholeheartedly disliked his dull, badly paid job at IBM.

It is challenging to understand and engage with this new capitalist work culture in which some subjects are well paid and have some autonomy and so on but nevertheless suffer in ways that poorly paid workers without autonomy also suffer. It is a characteristic of our era that these contemporary forms of work do seem less valid, or are framed as lifestyle choices. Traditionally, too, ethnography has 'studied down' with groups whose social or economic standing is less than the researcher's. This situation is not only a leftover from older traditions in anthropology, nor only because such people are easier to gain access to than 'studying up' with the more powerful or elites. Ethnography has often viewed these groups as being in need of the recognition that its research or interventions entails. The subject then also confers worthiness upon the researcher. ${ }^{17}$

This essay focuses on one of the participants in my project: Ryan. His experiences of churning have particular relevance to a major section of the essay's commentary on the IBM Global Human Capital Study. The glum presence of Coetzee's Youth sits in grass-roots protest before the study.

Ryan's dilemma initiated my research, and brought me to my opening question, how do individuals who are a part of these flexible work regimes in transnational organisations adapt and sustain their sense of self and character? Up 
until the mid 1990s Ryan ran barely profitable but personally fulfilling safaris across Kenya, intermittently returning to west coast America to his co-owned computer company and share trading. Then, not exactly swamped in money, Ryan would fly back to Africa, hire a truck and a crew, and take another set of tourists out to the deserts and the savannas. There was no game hunting on these trips, just a seeing of the sights in a low-key, close to the ground kind of way. He loved this work and the places it took him, the Kenyans he worked with, the lions and elephants, all the African fauna. There was purpose to his return trips to the US: to raise finance for the next safari, to see his mother and sister, and the buzz of a bit of share trading (again, not always profitable). His safari work and even the rationale to his work at home in the US were supported by his character, an earthy stoicism and a readiness to endure risks - of the physical kind while on safari-and financially in his business enterprises.

I asked Ryan about a photograph on his desk of a long-tusked African elephant, huge with ears wide, charging forward. It looks like something you'd see from a David Attenborough wildlife documentary. With a nonchalant shrug Ryan told me that after taking the photograph he turned and ran for his life.

Through friends, Ryan met Sonia, an Australian, in Los Angeles. They fell in love in his tent in the desert outside that city. A child was conceived and after following the intrepid Sonia across the globe while she was shooting a documentary, Ryan settled down in Sydney for the first of their babies and a less peripatetic kind of life.

When I first met him he was already working in sales at MiT, a major transnational IT corporation in North Sydney, the kind with fifty offices around the globe. He was an 'alliance partner sales manager' and was selling millions of contract dollars for the company a year, working out of one of the tower blocks that line the Pacific Highway all the way through to Gordon. The company developed and sold 'middle-ware' software to provide coherent systems that could integrate major facets of a client's computerised needs, be that client a university, government department or bank. Ryan was starting to make good money. Sonia was scratching a living in film from a Marrickville warehouse alongside the railway line-a suicide black spot. At that stage, though, their combined earnings were not enough for their growing family, which involved the cost of childcare, and the cost of assisting his 
mother back in LA, and the need to save a deposit for a house and mortgage in Sydney. First they lived in one or other of Sonia's siblings' houses, then bought a wretched inner-city cottage built by a welder and lived there with no hope of renovating in the foreseeable future.

By chance I met Ryan one day when we were both watching our toddlers swimming at the noisy local pool. The morning was hot and I was tired and he looked worn out too. I asked him how he was finding things.

'It's hell, absolute hell,' he said in his knowing LA voice.

What part of it was hell? Being at this pool right now, or fatherhood, or his work, or all of it? Potentially, it was all hell.

To succeed in sales, Ryan told me during our first interview, 'You have to want the money, be competitive and like the hunt.' The way he said this, he both believed it, and didn't. He could both align himself with the action, but see his words apart from himself as if they were a part of a PowerPoint presentation. 'Killing' wasn't an option, it was a 'must', he said. His words conveyed a little frisson, and a great deal of his American heritage that enables the comfortable use of these metaphors, but also a nonplussed feeling for what he was telling me. He was taking me on a tour of a place he didn't find that exciting. The adventurer now wore an ironed shirt, two-piece suit, receding hairline and a tie.

How on earth did Ryan mediate being a sales executive with having spent half a lifetime on safari? In many ways, the work Ryan does involves a lot of client relationship management and is not analogous to his past adventurous life. But there are some elements to his life within the transnationals that are comparable to the risks of hiking through the long grasses.

There is always the risk that Ryan's job won't be there for him the next day. Sennett suggests that risk-taking 'has become disorienting and depressing'. ${ }^{18}$ Where once risk was undertaken by entrepreneurs, inventors and frontiers-men and women, now risk has become the daily burden of the masses. Where risk taking was once heroic, it is now a social production of organisational management. Sennett's reading of risk shows how the bravura associated etymologically and historically with the notion has been leached away, dulled by fear or anxiety, or the recognition of the necessity rather than choice of risk. Today, the 'good' risk-taker 'has to dwell in ambiguity and uncertainty'.19 
An employee on the kind of individual contract typical for these executives can be retrenched at any time. The new east coast sales manager may want to flex muscle, showing superiors in Munich or Houston that he (and it is most often a he) has the mettle to rapidly replace staff. This process was described to me by one of my interviewees as to 'blood the new manager', a 'very nasty, ugly HR process'.

Or HR might show you to the door because you were too slow to bring in the contract, or one of your financial quarters' figures just wasn't good enough. The numbers to be achieved may have been shifted upwards to unattainable heights midway through the quarter, but as the sales executives I spoke to repeatedly said, 'It's all in the numbers.'

In fact, their jobs do not always rest with the numbers. Corporations are often in a state of internal flux not visible to the majority of the employees, for whom it is 'useless to attempt rational decision-making about one's future based on the current structure of one's company'. ${ }^{20}$ The sales executives may have done brilliant numbers, but it may also be the case that head office in Chicago wants to wind back the Asia-Pacific market which represents only two per cent of total sales: so, so what if that two per cent is booming. ${ }^{21}$ Retrenchments in Australia follow, and not only for the sales executives on flaky individual contracts, but also for some of their pre-sales engineers, sales marketing and administrative staff. In one set of retrenchments the resumé and reemployment trainer, hired by the company to assist the couple of hundred ex-employees, asked for a show of hands of those who had worked for the company for four to five years. There was a sea of hands raised, and she pointed out to the group that most of them had been retrenched around the four-and-a-half-year mark of their contract: at five years with the company, leave and redundancy entitlements improved.

In the six years I have tracked Ryan's employment, he has worked for six companies, beginning with MiT: he has left one of his own accord; has been retrenched due to managers' blooding by two; and during downsizings by three, the first following the dot-com bust, the most recent in 2009 as a consequence of the GFC. Ryan's narration of the changeability of the corporations he has worked for and the erratic measurement and evaluation of his work by his managers is invariably unemotional and rational. He can do this because, until recently, he has each time entered a better-paid position. The arc of his career has been on an upward curve. 
Ryan speaks of the stress and anxiety of these rapid changes in the past tense: having twice interviewed him in the days following a retrenchment I sense that he's unwilling at the time to vocalise his anxiety, waiting until he is in employment again to say, 'Yes, I was really stressed back then.' This is one of the ways he manages the crisis. He doesn't at the time blame the company, invariably offering the same rationale that is offered to him. It's never 'personal'. Sennett would say that for Ryan to fail to wrest some sense of continuity and purpose out of these flexible conditions would be literally to have failed himself. ${ }^{22}$ Faced with an undermining sales manager, a bad quarter's sales figures or a global financial crisis, he and the other sales executives must insist on the quality of their work: they carry within themselves the memory and knowledge of their achievements whether or not their numbers had been evaluated as satisfactory by a particular organisation. In this, the experience of retrenchment is entirely 'personal' and subjectively experienced. Dejours argues that work can constitute positive and specific challenges that reveal 'life to itself', but only if the individual is recognised and respected in their work: the culture of retrenchment, industries characterised by churning, the invisibility of one's work and the prevalence of monitoring and surveillance make this impossible. (Thus too, the increase in workplace pathologies.) The revelation of life to oneself, in oneself is elusive in the neoliberal work regimes, which demand the sacrificing of one's subjectivity in place of profitability and competitiveness. ${ }^{23}$

My interviewees could each make some sense of what happened at the various companies they'd worked for, and these stories integrated their own work with the input of others on their team; the role of their manager or pre-sales engineer, or software support guy. Success was accounted for as a result of their singular effort, while errors of judgement tended to be about the group, about lack of support from management or a support person. And why not own the success? Bar one, they were all still successful. They had good jobs, dined with bankers, were taken on 'high achiever' trips, and found new jobs when their companies downsized. Only failures would allow themselves to agree to have failed. And yet, as our conversations went deeper and more broadly into their lives, the corrosive effects of organisational 
flexibility, the imposition of risk and the precipice of failure became increasingly visible.

- HUMAN CAPITAL

Now that the words are out they sound stupid, and they are stupid. He is being manoeuvred into saying stupid things. But he should have expected that. That is how they will make him pay for rejecting them and the job they have given him, a job with IBM, the market leader. Like a beginner in chess, pushed into corners and mated in ten moves, in eight moves, in seven moves. A lesson in domination. ${ }^{24}$

Formal structures in corporations present an ideal, but in reality unattainable, state of affairs, with myriad disjunctions between the ideal and the day-to-day. In this next section I want to look at these disjunctions using a document of a very different kind to Coetzee's: 'The IBM Global Human Capital Study 2008', subtitled 'Unlocking the DNA of the Adaptable Workforce'. ${ }^{25}$ This report is relevant not only because IBM is an internationally significant player in the IT industry with a long history (dating back to its first iteration as the Tabulating Machine Company, 1896). The report is also an unusually public and 'unguarded' moment in management rhetoric. Nevertheless, despite being advertised in national Australian papers and online it was passed over in national press at its launch in late 2007. (It remains freely accessible through the IBM website.)

IBM was aiming to stimulate discussion and innovation in human capital management, to spruik its leadership credentials and build its corporate social capital. It intends to be a player of influence in what Castells describes as a perplexing array of interactions between technology, policy and action:

the new informational paradigm of work and labor is not a neat model but a messy quilt ... we must have the patience to abstract successive layers of social causation, to first deconstruct, then reconstruct the emerging pattern of work, workers and labor organisation that characterize the new, informational society. ${ }^{26}$

The study is an opportunity to look closely at evolving management practices at a 'design' stage. Commissioned by IBM, the researchers undertook to interview and report on human resource executives in four hundred companies of different size, 
industry and location. Companies in all major trade regions were approached, and interviews were conducted in forty countries, with Australia represented as part of the Asia-Pacific region.

Describing the reasons behind the research, the report discusses the global economy as one of flux, 'full of opportunity' but also 'swirling change'. Its focus is on 'the difficulties this expansion is causing today's organizations as they strive to make the best use of their most important assets: their workforces'. ${ }^{27}$

The report identifies four key areas that need to be addressed by organisations seeking to meet future economic growth 'challenges'. The first is to develop an adaptable workforce that can respond to market changes; second to identify and skill leaders so that their leadership can deliver results; third to develop 'talent management models' that cover the whole of the employee life cycle; and fourth to produce integrated data about employees' skills, knowledge and productivity that assists with strategic planning and rapid change.

For the moment I'll focus on the question of adaptation: the report's findings showed that the best financial performing companies have the most 'adaptable' workforces. Organisational adaptation is defined as being able to predict future skill requirements, identification and location of individuals with specific expertise, and collaboration within the organisation across internal boundaries, time zones and cultures. ${ }^{28}$ But, the report's interest in employee experiences of work and adaptation is oblique at best: it argues that organisations will need to embrace the 'entire employee life cycle' (without defining how a 'cycle' is determined), and will need to 'reach out' to labour pools that include, for instance, older workers and corporate alumni. It notes that Generation $Y$ has different needs and attitudes to more mature workers. ${ }^{29}$ This is no small issue, as it is well known that the current skills shortage is widespread across continents; more than a third of respondents indicated their employees' skills were 'not aligned with their current organisation priorities'.30 What is clear in reading this report is that the authors offer little in the way of concrete suggestions as to how to address these issues of encouraging and supporting 'adaptation' by employees to retraining and industry realignments. The IBM document clearly shows how very sketchy the transitions are once the focus is on the individuals being required to adapt. The document is powerful in its 
managerial rhetoric, and economic rationales, but is barely imaginable at the human level of the workers.

Today we know that the economic boom brought with it skills shortages and demand for workers with more loyalty and staying power than the corporations were prepared to offer in return; but also that the global economy offers even less security to corporations, finance providers and the shareholders still regarded as the principle stakeholders. As unemployment rises there will be shifts from talk of the value of workers as an organisation's most important asset to demands for even greater adaptations by workers as industries struggle with the global economic crisis.

There is no sense in the IBM document of individuals, of people with their own desires and histories, and certainly no evocation of work or life values. The language of human capital management is one of detachment from the flesh and blood of the people working for these corporations. Only remnants remain in the report from the informants' original statements of the fractures that Sennett and Dejours are concerned to investigate, arising from employees' humanity-not as human capital, but as persons with character and as people with work-evolved subjectivities.

One of the report's informants remarks that, 'Businesses change every day, and the development of a workforce that can cope with change is not easy.' ${ }^{31}$ How will HR make adaptation 'easier' for workers or enable the workforce to 'cope' with change? The report steps across this question, to stride forward on the basis that workers will adapt if HR follows the four tenets proposed: an adaptable workforce; skilled leaders; talent management models; and integrated data about employees.

Sennett argues differently, and Dejours' reports of the increase of workplace pathologies would also suggest otherwise. ${ }^{32}$ Only a 'certain kind of human being can prosper in unstable, fragmentary social conditions' of the kind being proposed by IBM. ${ }^{33}$ To maintain their subjectivity, this person needs to manage short-term relationships-while moving from task to task, or between jobs or places of work. They must 'improvise' their life-narrative, or 'even do without a sustained sense of self'. This person will need to develop new skills. But, in the modern economy the shelf life of skills is short; one IBM respondent said that the 'half-life of knowledge' in his industry was currently eighteen months. ${ }^{34}$ 
A further challenge to individual workers is, in Sennett's estimation, 'how to let go of the past'. Today's flexible organisation of the kind articulated by the IBM recommendations doesn't value past service or guarantee a continued place for its 'most important asset', the employees. Neither Ryan's employers or those of my other interviewees valued their employees' contributions beyond the last pay cheque. The end of the employment relationship rarely came with any formal acknowledgement such as a dinner, or a goodbye card from colleagues. A letter of reference was a bonus. One of my interviewees told me that, as a consequence, your pay packet had to include the 'fuck you money'.

That kind of money isn't available to everyone, however. So the ability to narrate your story in ways that express the importance of work in your life will be of even greater importance. The fraught task of understanding one's place and role in the flexible workforce is rendered all the more complex by the lack of continuity in work. Not only is it difficult to develop a narrative of self in the context of an uncertain future but the lack of a past that is meaningful exacerbates the dilemma.

A generation ago workplace routine had the place that flexibility has now, and it was this culture of routine that the young Coetzee found so oppressive and which he narrates so ably in Youth:

Despite his social origins, there is no reason why Bill Briggs [a fellow programmer] should not succeed in IBM ... That is the strength of IBM: men of all kinds can get to the top because all that matters to IBM is loyalty, and hard, concentrated work. Bill Briggs is hard-working, and unquestioningly loyal to IBM. Furthermore, Bill Briggs seems to have a grasp of the larger goals of IBM and of its Newman Street data-processing centre, which is more than can be said of him. ${ }^{35}$

In fact, for Bill Briggs to do his work, he also needed to 'disobey' what had been prescribed, to find solutions to unexpected events or changes. In Coetzee's portrait, Briggs was apparently content to be giving of himself to his work. Nevertheless, Briggs and other of Coetzee's former colleagues would have been made redundant or shifted about in the company long ago. But the IBM study suggests that such retrenchment practices need to be rethought (not because of the damage to employees), because hiring the right skilled staff is now proving to be difficult. 
Perhaps chaps like Briggs, who might have seemed at the turn of the century to be redundant, should have been kept on after all.

The IBM recommendations reminded me of the way that Ryan's employment with a European transnational ended. Leaving Euro has been his most fraught exit to date, certainly more troubling in its precipitation than his earlier redundancy at MiT. (That hadn't been easy, but at least it was part of a company-wide restructure resulting from global downsizings following the dot-com crashes of 2001-2002. Still, with that first sacking, Ryan was fairly anxious as he hadn't yet established himself in the industry and wasn't as familiar with the retrenchment culture as he is now, several departures on.)

In regular staff meetings with his Euro sales manager, he'd explained that certain issues at a major client account meant that the process of finalising the contract could not be quickened. Undermined by Euro's insistence on speed, Ryan argued with his manager that maintaining a good relationship with a client was important for the longer term. But, complicating his immediate quarter's results was Euro's short-term strategy to increasing income by reviewing old contracts with existing clients and finding ways to penalise the client. For instance, a necessary maintenance upgrade, which only Euro could provide, turned out to be outside the annual maintenance fee. Euro wanted a substantial and additional payment for it. As Ryan said, this practice was not within the norm of industry practice. He and his colleagues didn't want to be the messengers. Messengers get blamed. It was bad for their reputations as reliable, trustworthy sales execs-reputations that the executives carried with them beyond their employment with a particular company. Their reputation was their social capital, existing in their relations with others, and the shared histories of these relations amongst the executives and clients. This created a dilemma, because to get the numbers in on time and satisfy management, he'd need to compromise his integrity and aggravate his customers; while this might be a competitive strategy in the short term he'd feel bad about it, and as Ryan said, word gets round:

I had good relationship with the CIO of the ASC, and we had coffee after I left and she said, 'Rotten people to do business with,' and I said, 'Look I just want to tell you I'm leaving because it's a small industry and I don't agree 
with what they're doing with the customers' ... Basically I decided to leave because you don't want to get your name sullied in such a small area.

What began as competitive strategies designed at a corporate level filtered down to become directives that had to be enacted by the workers. These directives affected not only the workers' relationships with clients, but also with themselves; the directives required the sales staff to accept a bad practice as good for the company's short term income.

At Euro Ryan did get the contract signed, making his numbers, but not in the financial quarter that his manager wanted. The manager now pestered and criticised him, looking for minor faults in his work. There was the issue of an unanswered email; why hadn't Ryan responded to the client's email? Knowing he was doomed to lose in this exchange, Ryan nevertheless explained that it occurred in the week when Euro's spam filter wasn't functioning, and the genuine email had been missed amongst the flood of spams. The manager wasn't satisfied and the discussion about the missed email went back and forth. When Euro's best performing sales executives gathered in Portugal for an 'Achiever's Week', Ryan already had his $\$ 200 \mathrm{k}$ bonus in the bank from the contract he'd finalised. What was unexpected was his manager naming himself in relation to the contract on the Achiever's night. On return to Sydney, Euro's human resources CO told Ryan he was on a performance review.

Rather than wait out that process, which 'doesn't pay because there are a lot of ways to measure sales people, a lot of which are not objective', Ryan moved companies. As James, another interviewee told me, a performance review or 'performance counselling' is the signal that you're on the way out. 'At Microsoft,' he said, having worked there for some years,

they used that as a way of getting rid of people who had been in the company over about seven years. There was edict in the company that said most of our people have been here a long time ... they have entrenched values and we need to drive our attrition rates up from two per cent to ten per cent ... it was just a raw harvest of anyone who was at a certain age group or length of service with the company. So that is how I and a number of others left Microsoft around that time.

Within weeks James went from Microsoft to a company fifty per cent owned by Microsoft: 
So rather than having any sort of internal transfer or a nice conversation around, you know we think your skills are better worked over there, they put you through a performance improvement process ... the reason I'm focused on this is because it is a point that I think is worth making and one of the things that I have seen the IT industry do particularly poorly is managing people. It is a very high churn industry.

Speaking of his manager Ryan told me,

It wasn't him alone. I think there [was] incredible pressure throughout the whole company. It [was] very short-term and they [were] just looking after the numbers not the relationships ... Two bad quarters and you're out.

The IBM report castigates corporations for being blind to their own ways here, that is, the endemic churning of employees:

Many believe their corporate reputations will allow them to attract and retrain the people they need. Yet, changing trends in workforce demographics and mobility patterns suggest they may need to challenge this perception and consider investing more resources in recruiting, selection and retention. 36

Elsewhere the IBM report mentions employees' 'weakening allegiance to the workplace', but gives it scant attention, only briefly returning to it in the sub-section 'Image counts: Putting your best foot forward in the talent marketplace'. Here, the profound issue of work-life balance is glanced over within the narrow rubric of 'image'. In response to the question, 'What do you believe are the most important characteristics that help retain candidates within your organization?' only a little over 30 per cent of the human resources respondents identified 'Company values are aligned with personal values'. ${ }^{37}$ In Youth, Coetzee relates a conversation between the narrator and his manager upon the young narrator's resignation from the company. The manager is coolly affronted that the programmer should value social interaction enough to leave IBM in the absence of it. He belittles the young employee, implying that to want the satisfaction of friendship at work is ridiculous. This passage is a narrative example of the derailing experience that teamwork can bring about when the individual shares little with the group, and the suffering that 'subjection' to the group entails: 
'I don't find working for IBM very satisfying at a human level. I don't find it fulfilling.'

'Go on.'

'I was hoping for something more.'

'And what might that be?'

'I was hoping for friendships.'

$\cdots$

'What else? If there is something else on your mind, this is your chance to bring it out.'

'Nothing else.'

'Nothing else. I see. You are missing friendships. You haven't found friends...

And for that you want to resign.'

'Yes.'

Now that the words are out they sound stupid, and they are stupid. He is being manoeuvred into saying stupid things. But he should have expected that. That is how they will make him pay for rejecting them and the job they had given him, a job with IBM, the market leader ... A lesson in domination ... With a brusque gesture McIver terminates the interview. ${ }^{38}$

-INVISIBLE WORK

Under the shadowless glare of the neon lighting, he feels his very soul to be under attack. The building, the featureless block of concrete and glass, seems to give off a gas, odourless, colourless, that finds its way into his blood and numbs him. IBM, he can swear, is killing him, turning him into a zombie. Yet he cannot give up. Barnet Hill Secondary Modern, Rothamsted, IBM: he dare not fail a third time. Failing would be too much like his father. Through the grey, heartless agency of IBM the real world is testing him. He must steel himself to endure. ${ }^{39}$

Though the narrator of Youth would seem to be on the verge of a breakdown, from his employer's point of view his work is satisfactory. But, his managers have no idea of how great his contribution is to the company-if measured by the difficulty of producing the contribution. He's driven to continue there not through the kind of 
loyalty that Bill Briggs feels, but by memories of his other failures. He is simply glad to have a job and to have escaped South Africa. The young narrator is suffering and feels the place is 'killing' him, but he nevertheless functions. This is part of the contradiction of his living that the memoir explores, that this work at once brings out the narrator's alienation and his will not to be effaced at work. In Dejours' terms this agreement comes about from one of two motives. Without these normative agreements, individualism would lead to conflict and potentially to violence, with the result that the social and ethical conditions needed to support life in work would be destroyed. Thus, 'The individual renunciations demanded by cooperation are thus accepted in order to avoid this deadly process. ${ }^{\prime 40}$ Conversely, by participating in the group activity of work, the worker is potentially able to obtain the recognition of others for their experience of work. And this, potentially, is when working is sustaining of subjectivity: when the real work achieves visability, recognition becomes possible-the recognition resulting from judgments about doing and working, and not about the person who works'. ${ }^{41}$ In Ryan and his colleagues' world of work, only slivers of their work was allowed visibility and given recognition: getting the contracts in. But this was not the whole of their work contribution, by any means.

The IBM study's final recommendation, 'Driving Growth Through Workforce Analytics', proposes ways to monitor and improve the management of 'human capital'. The challenge for HR, it argues, will be to produce better metrics on individual workers, and very importantly to contribute the data more strategically by working closely with chief officers across all organisational divisions, as well as using the data to discipline, reward, retrain or shift individual workers. There is more than a trace of the desire for a metricated Foucauldian panoptic surveillance being recommended in the IBM report. A range of software is discussed, but, whatever is finally chosen by companies to undertake this surveillance, the focus must be this:

$\mathrm{HR}$, working more closely with the business, can monitor and influence the behaviours that have a direct impact on business performance. The more aligned the workforce metrics are with business priorities, the greater the ability to improve workforce performance to meet business goals. [my italics] 
Self-valuing will be an increasing challenge to individuals if metrication of the human capital contribution increases in kind and detail. Though individually we might know that metrics can't articulate the whole experience of work and our subjective contribution, not receiving recognition does its damage. Faced with his manager's fact sheet of sales figures for the quarter, Ryan could only vainly protest that the figures didn't show what he knew, that the finalisation of the contract would take a little more time, and that trust and patience was called for.

Ryan had understood that staying at Euro would require him to either fight his case, or risk being sacked on another pretext. He immediately set about finding new employment, with good references from clients to hand. Within a couple of weeks he was offered an even better-paid job. When we spoke he'd finished up at Euro, then he'd had a week up the coast snorkelling with his children and was looking relaxed and fit. He was yet to start at the new company, Chase.

I asked him how did he know Chase would be any better? After all, following a longish stint at MiT from the late 1990s until 2003, he was now about to enter his fourth company. Ryan shrugged. As Sennett observes, the instability of working for flexible organisations makes risk seem normal and ordinary. ${ }^{42}$ Ryan's shrug was also his way of saying, 'I can't afford to panic.' This instability is woven into the very fabric of the neoliberal work culture, and Ryan had to resist it, with what Sennett warns can become a static assertion of values, rather than a narrative that shapes and evolves with experience and the flow of time.43 Ryan set about ascertaining whether Chase was a good company to move to:

Well you don't know, absolutely not. It's like going on a date-how do you know? How do you know if this guy was an arsehole, how do you know the next guy is going to be better? You don't know ... But also I did a lot of due diligence; talked to people and did a lot of research on the web and found out where they are going ... they are very good vendors to work with from a customer standpoint. I thought that was a pretty good recommendation.

Always, in his final assessments of how best to do his work, Ryan came back down to his own character, that element that is so difficult to measure. He knew himself, and his good clients' recommendations counted for something. For Ryan it was now necessary to believe that he had the grist to withstand what was to come. 
Management have little interest in character and seems not to measure or find ways to recognise character beyond the interview process with the MyersBriggs Type Indicator approach to assessing suitability for the job. The metrics don't get at this, that these employees have the ability to maintain relationships. These relationships are not valued when in the globalised corporations Head Office is at a distance to Australian management and all it is measuring are regional sales figure and timeframes that become impossible as they don't relate to the actual relationships being sustained in Sydney or Brisbane or Perth. Character remains unknown and unmeasured and this becomes the company's loss, but the 'loss' itself is not measured because it wasn't known in the first place. The companies don't fully know the capital assets of their human resource, their staff, and the metricated measurements proposed in the IBM report are not going to give them that deep knowledge.

\section{-SURVIVING CHANGE}

Since arriving in Australia in the early 1990s and working for MiT, Ryan went back and forth to Los Angeles, Houston, Melbourne, to cities in South East Asia and to Berlin. At meeting tables, in flight terminals and over the internet he met with his colleagues and alliance partners, many of these colleagues themselves working in new firms, same industry, adapting more or less well, shape shifters and survivorssome of them.

Modern organisations believe that to be competitive internal reorganisation is necessary. Chase, no innovator here, had a poor financial half-year in Australia, and the new manager was finding ways to shed staff. Ryan and others at Chase were made to reapply for their jobs. They were then told that they'd 'all performed badly' in this process. Ryan was pissed off, but went in to work each day determined to do a good job while the final decision as to who would be retained and who 'let go' was awaited.

Not detailed in this essay are his next two stints at companies five and then six, from which he was retrenched in early 2009 during GFC downsizing. Unemployed until early 2010, Ryan unsuccessfully attempted to use his sales experience elsewhere and move into a new industry. He again readjusted his expectations and stopped seeking to 'match or improve his income and position', 
moving out of sales to the training section of an IT transnational. His current shortterm contract with company number seven earns him half what he earned previously, but nevertheless he's 'not worried'.

This culture of risk, uncertainty and instability may be one that those at the top thrive on, but for most workers:

Such practical realities require, however, a particular strength of character-that of someone who has the confidence to dwell in disorder, someone who flourishes in the midst of dislocation. ${ }^{44}$

Sennett says such a person is a rare thing. Is Ryan this person? He has been for some years, but for how much longer and for how many more transnationals he can be that person, is anyone's guess. In his late fifties and aging during this current economic instability, he will most certainly need to find a narrative that sustains his sense of self through the uncertainties of temporary employment and a gutted income.

Jane Messer's recent work engages practice-led research in the areas of fiction, ethnography and cultural studies. The conjoined projects include a series of papers, Writing Corporate Culture: An Australian Narrative, and a novel, The Happiness Project. Her most recent book publication is the novel Provenance (2007).

\section{-ACKNOWLEDGEMENTS}

The author would like to thank Dr Liz Ferrier, School of Business, University of QLD, for her invaluable comments and suggestions in the drafting of this essay, and her generosity in offering them.

-NOTES

${ }^{1}$ J.M. Coetzee, Youth, Vintage, London, 2003, pp. 46-7.

2 Coetzee, p. 47. 
${ }^{3}$ Manuel Castells, The Information Age: Economy, Society and Culture: The Rise of the Network Society, vol 1, 2nd edition, Blackwell Publishing, Oxford, 2000.

4 David Harvey, A Brief History of Neoliberalism, London: Oxford University Press, 2007.

${ }^{5}$ Richard Sennett, The Corrosion of Character: The Personal Consequences of Work in the New Capitalism, W.W. Norton \& Company, New York, 1998.

${ }^{6}$ By narrative I mean affective prose, be it in the form of the novel, creative non-fiction (personal essay, and so on) or memoir. My inclusion of the genres of creative non-fiction and memoir allow for ethnographic elements, and acknowledges the narrativity involved in ethnographic writing. Narrative is thus not restricted to only fictional narratives. Shlomith Rimmon-Kennan defines 'narrative fiction' as the succession of fictional events with the term 'narration' suggesting a communication process; the verbal medium used in the communication distinguishes it from other kinds of communication such as film, photography or dance. See Shlomith Rimmon-Kennan, Narrative Fiction: Contemporary Poetics, Routledge, London, 2002, p. 3.

${ }^{7}$ Certainly the stories of work in television narratives such as Just Shoot Me, Boston Legal, and CSI are fantasies that have very little to do with our lived experience of work. Australian-produced programs such as Packed to the Rafters, All Saints or Neighbours are equally fantasy representations of the experience of work as a place for social exchange. Undertaking a survey of Australian fiction and creative non-fiction writing on corporate and business culture from first settlement to 2007, I produced almost no samples.

${ }^{8}$ Sennett, p. 10.

${ }_{9}^{9}$ Christophe Dejours, 'Subjectivity, Work and Action', Critical Horizons, vol. 7, no. 1, 2006, p. 77. For commentary on Dejours' contribution to social theories of work, see Anders Petersen and Rasmus Willig, 'Work and Recognition', Acta Sociologica, vol. 47, no. 4, 2004; Jean-Philippe Deranty, 'Work and the Preacrisation of Existence', European Journal of Social Theory, vol. 11, no. 4, 2008.

${ }^{10}$ Christophe Dejours, quoted from J.D. Reynaud, Lex regles du jeu, l'action collective et la regulation sociale, Armand Colin, Paris, 1989.

${ }^{11}$ Jean-Philippe Deranty characterises Dejours' research as defining work as 'the activity required of the subject to bridge the gap between the prescriptive characterisation of the tasks and the reality of his or her performance'. For this reason, the fullness of our work is not recognised. See endnote 9. 12 Dejours, p.78

13 James Wood, 'A Life of their Own', Guardian, 26 January 2008,

<http://www.guardian.co.uk/books/2008/jan/26/3>; James Wood, 'Tell Me How Does it Feel?', Guardian, 6 October 2001, <http://www.guardian.co.uk/books/2001/oct/06/fiction>; James Wood, How Fiction Works, Jonathan Cape, London, 2008.

14 The names of the interviewees and the companies that the participants work/ed for have been changed at the request of the interviewees. My fieldwork at MiT was conducted in 2003, and the 
interviewees recorded in 2006 and 2009 in Sydney. All quotes from interviewees in this essay are from these interviews.

15 James Clifford, The Predicament of Culture, Harvard University Press, Cambridge, Mass., 1988.

16 I am indebted to Sennett's conversations with Rico in The Corrosion of Character for this approach.

${ }^{17}$ Laura Nader quoted in George Dearborn Spindler, Lorie A. Hammond, Innovations in Educational Ethnography, Routledge, London, 2006, 236-7. Antonia Lima reports on her work with business family elites in Portugal and the difficulty of access in 'Ethnography as an Asset: Elites' Uses of Ethnographic Work', paper presented at the conference Ethnografeast 111: Ethnography and the Public Sphere,

2007, at <ceas.iscte.pt/ethnografeast/papers/antonia_lima.pdf>, accessed 7 March 2009.

18 Sennett, p. 7.

${ }^{19}$ Sennett, pp. 80, 85.

${ }^{20}$ Sennett, p. 85, quoted from Scott Lash and John Urry, The End of Organised Capitalism, Polity Press, Cambridge, 1987.

21 My interviewee, Thomas, did 200 per cent over quota with his Asia-Pacific clients, but was retrenched because the region was no longer the focus for his transnational. After this retrenchment Thomas was unable to get back into the industry. In his mid forties, he was told he was 'too old'. See Jane Messer, 'Up the Highway to Campus Optus', Text, no. 5, April 2009,

<http://www.textjournal.com.au/speciss/issue5/messer.htm>.

22 Sennett, p. 122.

23 Dejours, p. 85.

24 Coetzee, p. 07.

25 The IBM Global Human Capital Study 2008, at <http://www-

935.ibm.com/services/us/gbs/bus/html/2008ghcs.html>, accessed 7 February 2008.

${ }^{26}$ Castells, p. 256.

27 IBM, p. 2.

28 IBM, pp. 2, 10.

${ }^{29}$ IBM, p. 4.

${ }^{30}$ IBM, p. 27.

31 IBM, p. 9.

32 Dejours, p. 86.

${ }^{33}$ Richard Sennett, The Culture of the New Capitalism, Yale University Press, New Haven, 2006.

34 IBM, p. 11.

35 Coetzee, p. 50.

36 IBM, pp. 27, 35.

37 IBM.

38 Coetzee, pp. 107, 108.

${ }^{39}$ Coetzee, p. 47. 
40 Dejours, p. 84

41 Dejours, p. 85.

42 Sennett, p. 81.

43 Sennett, p. 30.

44 Sennett, p. 62. 